\title{
PROGRAMA PARQUE ESCOLA: USO PÚBLICO DAS UNIDADES DE CONSERVAÇÃO EM GUAPIMIRIM, RJ
}

\author{
Theresa Cristina de Oliveira Chaves ${ }^{1}$ \\ Daiane Lopes de Freitas ${ }^{2}$ \\ Tamires Rangel de Sá Maceira ${ }^{3}$ \\ Luiz Fernando Saraiva da Silva ${ }^{4}$
}

\section{RESUMO}

A Educação Ambiental pode atuar no processo de informação, conscientização e sensibilização das pessoas. Tendo em vista a degradação ambiental atual e a necessidade extrema de preservação, o Setor de Educação Ambiental da Secretaria Municipal do Ambiente de Guapimirim desenvolveu o Programa Parque Escola, que propõe a prática de atividades voltadas a Educação Ambiental dentro das Unidades de Conservação existentes no município de Guapimirim (ARIEs, Parques, APAs, e Estações Ecológicas), tendo como público alvo alunos das redes municipal, estadual e particular de ensino, idosos, pacientes do centro de atendimento psicossocial e técnicos. As atividades desenvolvidas incluem trilhas interpretativas, soltura de animais silvestres, plantio de mudas, visitas técnicas, palestras temáticas e cursos. Em pouco mais de um ano, o Programa Parque Escola levou educação ambiental a mais de 360 pessoas, gerando reconhecimento e valorização dos espaços públicos pelos munícipes, estimulando o uso público sustentável e internalizando valores de corresponsabilidade na gestão e proteção das Unidades de Conservação.

Palavras Chave: Educação Ambiental, sensibilização, Parque Escola

\section{ABSTRACT}

Environmental education can act on the information process, awareness and educating people. Given the current environmental degradation and the dire need of preservation, the Environmental Education Sector of SEMA (Secretaria Municipal do Ambiente de Guapimirim) developed the Park School Program that proposes the practice of activities related to environmental education within Guapimirim

\footnotetext{
${ }^{1}$ Discente de Pós Graduação em Educação Ambiental Urbana da Escola Superior Aberta do Brasil e Coordenadora do Setor de Educação Ambiental da Secretaria do Ambiente de Guapimirim. E-mail: theresachaves@hotmail.com

${ }^{2}$ Licenciada em Ciências Biológicas pela Universidade Salgado de Oliveira, Bióloga da Secretaria do Ambiente de Guapimirim e Docente da Secretaria Estadual do Rio de Janeiro. E-mail: daianebio@yahoo.com.br

3 Mestranda de Clínica e Reprodução Animal pela Universidade Federal Fluminense e Médica Veterinária da Secretaria Municipal do Ambiente de Guapimirim. E-mail: tamires_rangel@ @otmail.com

${ }^{4}$ Mestre em Ciência Ambiental pela Universidade Federal Fluminense e Secretário Municipal do Ambiente de Guapimirim. E-mail: luizfernandopedagogia@ yahoo.com.br
} 
Conservation Units (ARIEs, Parks, APAs and Ecological Stations), having as target students from public and private education, elderly people, patients of psycossocial center and technicians. The activities include interpretive trails, release of wild animals, planting seedlings, technical visits and courses. In just over a year, the Park School Program led environmental education to more than 360 people, generating recognition and appreciation of public spaces by residents, encouraging sustainable public use and internalizing responsibility values in the management and protection of protected areas.

Keywords: Environmental education, awareness, Park School

\section{INTRODUÇÃO}

As Unidades de Conservação (UCs) são espaços territoriais destinados à preservação dos ecossistemas naturais, possuem limites definidos e existem sob um regime especial de administração, ao qual se aplicam garantias adequadas de proteção (art. 2 da Lei n ${ }^{\circ}$ 9.985/00). As UCs são criadas com o intuito de garantir a sobrevivência da fauna e da flora (biodiversidade), os recursos genéticos e também para proteger os processos ecológicos essenciais e locais de grande beleza cênica, como montanhas, serras, cachoeiras, cânions, rios e lagos (MMA, 2010).

A forte pressão que as UCs vêm sofrendo, decorrentes das atividades antrópicas e da ocupação urbana em seu entorno, colocam em risco os serviços ambientais prestados como: preservar os recursos hídricos, a paisagem, a estabilidade geológica, a biodiversidade, o fluxo gênico de fauna e flora, proteger o solo, assegurar o bem-estar das populações humanas, entre outros.

A degradação do ambiente e a necessidade da preservação é uma preocupação mundial. A educação ambiental pode atuar no processo de informação, conscientização e sensibilização das pessoas, estimulando seu senso crítico em relação às questões ambientais levando, consequentemente, à vivência harmoniosa com a natureza e a melhoria da qualidade de vida.

Após realizar um diagnóstico ambiental das escolas municipais, o Setor de Educação Ambiental da Secretaria Municipal do Ambiente (SEMA) do Município de Guapimirim criou o Programa Parque Escola, que propõe a prática de atividades de educação ambiental nas UCs em Guapimirim, como Parques, Áreas de Relevante Interesse Ecológico, Áreas de Proteção Ambiental e Estações ecológicas.

O Programa permite o convívio das pessoas nas UCs, favorecendo a compreensão sobre a importância da preservação dos recursos naturais e do papel da população nas relações com o meio em que vivem. Podem, ainda, ajudar a despertar o interesse e o pensamento crítico, referentes aos fatores ambientais de forma mais abrangente. 


\section{OBJETIVOS DO PROGRAMA PARQUE-ESCOLA}

\section{Estímulo à inserção das UCs como temática no ensino formal}

- Articular com a secretaria de educação e demais instituições municipais o desenvolvimento e implantação de metodologias que utilizem as UCs como cenários para o ensino e, também, como espaços para a adoção de práticas sustentáveis por meio da educação ambiental na educação escolar (formal), desenvolvida no âmbito dos currículos das instituições de ensino públicas e privadas, englobando a educação básica nas seguintes modalidades: educação infantil; ensino fundamental, ensino médio; educação especial; educação profissional e educação de jovens e adultos;

- Estimular a inserção participativa de questões ligadas à realidade e ao cotidiano das UCs, bem como à conservação da sociobiodiversidade, como temas geradores em Projetos Político-pedagógicos das instituições de ensino de Guapimirim, despertando o interesse e estimulando o desenvolvimento de atividades com jovens de comunidades locais e do entorno das UCs, favorecendo a inserção dessas populações como agentes parceiros nas ações de conservação e "fiscalização".

\section{Inserção das UCs como temática nos processos educativos não-formais}

- Desenvolver programa de capacitação voltado aos professores da rede pública e equipe técnica da SEMA Guapimirim, visando fortalecer práticas socioambientais , integrando estes profissionais às ações e práticas educativas voltadas à sensibilização da coletividade sobre as questões ambientais e à sua organização e participação na defesa da qualidade do meio ambiente;

- Qualificar e viabilizar a participação de todos os atores sociais envolvidos direta ou indiretamente com as UCs por meio da realização de oficinas, palestras e eventos técnicos em datas comemorativas;

- Promover maior integração entre ações de fiscalização e de Educação Ambiental;

- Oferecer aos visitantes (alunos, técnicos, professores e munícipes da $3^{\text {a }}$ idade) qualidade na experiência vivida na sua passagem pela UC, proporcionando reflexões entre esta experiência e as questões ambientais da região, potencializando sua ação multiplicadora;

- Construir e disseminar de forma participativa os diversos conhecimentos sobre práticas sustentáveis.

\section{ÁREAS DE ABRANGÊNCIA DO PROGRAMA}

\section{Unidades de Conservação que se inserem no programa Parque-Escola}

No Município de Guapimirim estão situadas sete unidades de conservação: Parque Nacional da Serra dos Órgãos (PARNASO), Parque Estadual dos Três Picos 
(PETP), Área de Proteção Ambiental (APA) Guapimirim, Estação Ecológica (ESEC) da Guanabara, APA Guapi-Guapiaçu, Parque Municipal das Águas e Área de Relevante Interesse Ecológico (ARIE) Citrolândia.

As atividades do Programa Parque-Escola foram desenvolvidas: na APA Guapimirim, na ESEC Guanabara, no Parque Nacional da Serra dos Órgãos, no Parque Estadual dos Três Picos e na ARIE de Citrolândia.

\section{- APA de Guapimirim}

A APA Guapimirim foi criada em 25 de setembro de 1984, resultado de um movimento ambientalista da sociedade civil organizada e da comunidade científica. Tem como principal objetivo proteger os remanescentes de manguezais situados no recôncavo da Baía de Guanabara e assegurar a permanência e sobrevivência de populações humanas que mantêm uma relação estreita com o ambiente, vivendo dos seus recursos naturais e mantendo ainda características tradicionais no convívio com a natureza. Abrange parte dos municípios de Magé, Guapimirim, Itaboraí e São Gonçalo (IBAMA, 2004).

A APA Guapimirim abrange a área de manguezal mais preservada do Estado do Rio de Janeiro. A pesca esportiva, o passeio de barco e a observação das várias espécies de pássaros proporcionam lazer e descanso aos visitantes, que ainda são contemplados com o espetáculo do entardecer, quando o sol se põe tendo ao fundo a Baía de Guanabara (IBAMA, 2004).

\section{- ESEC Guanabara}

A ESEC Guanabara, foi criada em 15 de fevereiro de 2006, possui cerca de 2.000 hectares, abrangendo parte dos municípios de Guapimirim e Itaboraí. É a área mais conservada de toda Baía de Guanabara, apresentando características ecológicas e biológicas compatíveis com os manguezais isentos de intervenção humana e agressiva (ICMBio, 2012). A ESEC fica localizada em terras da Marinha do Brasil e é utilizada para pesquisas científicas e educação ambiental (ICMBio, 2012).

É a última área da Baía de Guanabara a apresentar características cênicas extremamente próximas ao período anterior à colonização europeia do País. Constitui um dos últimos trechos de manguezal contínuo de médio porte, além de abrigar espécies ameaçadas de extinção, no estado do Rio de Janeiro (ICMBio, 2012).

\section{- Parque Nacional da Serra dos Órgãos}

O Parque Nacional da Serra dos Órgãos (PARNASO), abrange uma área de 10.653 hectares com $71 \mathrm{Km}$ de perímetro. Abrange os municípios de Petrópolis, Teresópolis, Magé e Guapimirim onde está situada uma de suas sedes. Foi criado em Novembro de 1939, pertencendo à primeira geração de Parques Nacionais Brasileiros e tem valor científico e estético. De excepcional valor paisagístico atrai inúmeros turistas 
e constitui um importante valor de desenvolvimento local. As belezas naturais do parque e seus atrativos turísticos atraem muitos turistas (ICMBio, 2007).

\section{- Parque Estadual dos Três Picos}

O Parque Estadual dos Três Picos (PETP), localiza-se na região Centro-Norte Fluminense do Estado do Rio de Janeiro, foi criado oficialmente pelo Decreto Estadual $\mathrm{n}^{\circ} 31.343$ de 05 de junho de 2002, com área de 46.350 ha e um perímetro de $512 \mathrm{Km}$, passando a ser a maior Unidade de Conservação da Natureza de Proteção Integral Estadual. Representando um dos mais expressivos fragmentos da Mata Atlântica, o parque abrange áreas de 5 municípios: Cachoeiras de Macacu, Nova Friburgo, Teresópolis, Guapimirim e Silva Jardim, possuindo inestimável beleza cênica, com grande números de nascentes, rios e cachoeiras, sendo um dos principais atrativos turísticos da região (INEA, 2013).

\section{- ARIE de Citrolândia}

A ARIE de Citrolândia foi criada pela Lei Municipal No 497 de 05 de agosto de 2004, está localizada no Bairro de Citrolândia, no Município de Guapimirim, RJ. Essa área apresenta significativa sensibilidade ambiental, que exigem ocupação e uso urbano disciplinado, no sentido de proteger os recursos naturais, especialmente parcelas da Mata Atlântica, os solos e os recursos hídricos, superficiais e subterrâneos.

\section{Parceria SEMA-Guapimirim e UCs}

Por meio da participação dos Conselhos Gestores das Unidades de Conservação, o município de Guapimirim dinamiza várias estratégias de uso sustentável destas com a inclusão de escolas, Centros de Atendimento Psicossocial (CAPS), Programas da terceira idade etc., em visitas guiadas pela equipe técnica do Setor de Educação Ambiental da Secretaria Municipal do Ambiental.

Esta estratégia é voltada ao (re) conhecimento, valorização destes espaços públicos pelos munícipes e processos inclusivos de participação social, fortalecimento da cidadania oportunizados por estes. Estimular o uso público sustentável e internalizar valores de corresponsabilidade na gestão e proteção das Unidades de Conservação.

A implementação da Gestão Participativa é um processo orientado por princípios da Educação Ambiental com um o objetivo de tornar os Conselhos verdadeiros espaços de expressão, representação e participação dos atores sociais, buscando um envolvimento ativo e a participação cidadã para a preservação e a conservação dos ecossistemas.

\section{O PROGRAMA PARQUE ESCOLA}

O Programa Parque Escola, foi iniciado em setembro de 2013, a partir da elaboração de um diagnóstico ambiental das 22 unidades de ensino municipais, no qual foi constatado a deficiência destas no uso público das unidades de conservação do entorno. A equipe de educação ambiental do Programa é composta por dois biólogos, 
uma gestora ambiental, uma veterinária, um técnico ambiental e um educador ambiental. $\mathrm{O}$ programa oferece à população (principalmente alunos das redes pública $\mathrm{e}$ particular de ensino, situados no município de Guapimirim), atividades de educação ambiental em UCs localizadas no município de Guapimirim, por meio de ações como: trilhas interpretativas, soltura de animais silvestres, plantio de mudas, visitas técnicas, cursos e palestras, associados ao lazer.

\section{- Trilhas interpretativas}

Através do prévio agendamento na Secretaria do Ambiente pela coordenação da escola, alunos da rede pública de ensino do município de Guapimirim, assim como idosos atendidos por projetos da Secretaria de Ação Social do município, participam de trilhas interpretativas no Parque Nacional da Serra dos Órgãos - Sede Guapimirim.

As trilhas abrangidas são:

- Circuito Poço Verde (600 metros até o poço verde e 200 metros até o Poço da Preguiça).

- Trilha do Poço da Ponte Velha (aproximadamente 600 metros).

- Trilha da Capela (aproximadamente 200 metros).

- Trilha do Poço do Sossego (400 metros).

$\mathrm{Na}$ chegada ao Parque, os alunos ou idosos, assistem à palestra oferecida pelo Parque sobre a sua gestão e apreciam a maquete que mostra toda área da UC e localização dos poços e trilhas. Em seguida, assistem à palestra ministrada pela Equipe de Educação Ambiental da SEMA-Guapimirim e, nesse momento, são instruídos sobre como deve ser a postura e comportamento durante a trilha e os pontos que serão observados. Também são abordados durante a palestra, temas como unidades de conservação, sustentabilidade, uso público das UCs, impactos e preservação ambiental.

Durante a trilha, os alunos ou idosos são divididos em grupos de 10, sempre acompanhados por um técnico da SEMA ou professor. São realizadas observações durante toda trilha a respeito da flora e fauna nativas e para cada ponto pré-determinado é feita uma parada para explicação sobre a história da trilha e curiosidades sobre o local.

No final são propostas atividades de lazer como banhos de cachoeiras, piqueniques, atividades físicas, sempre interagindo com a natureza (Figura 1). 


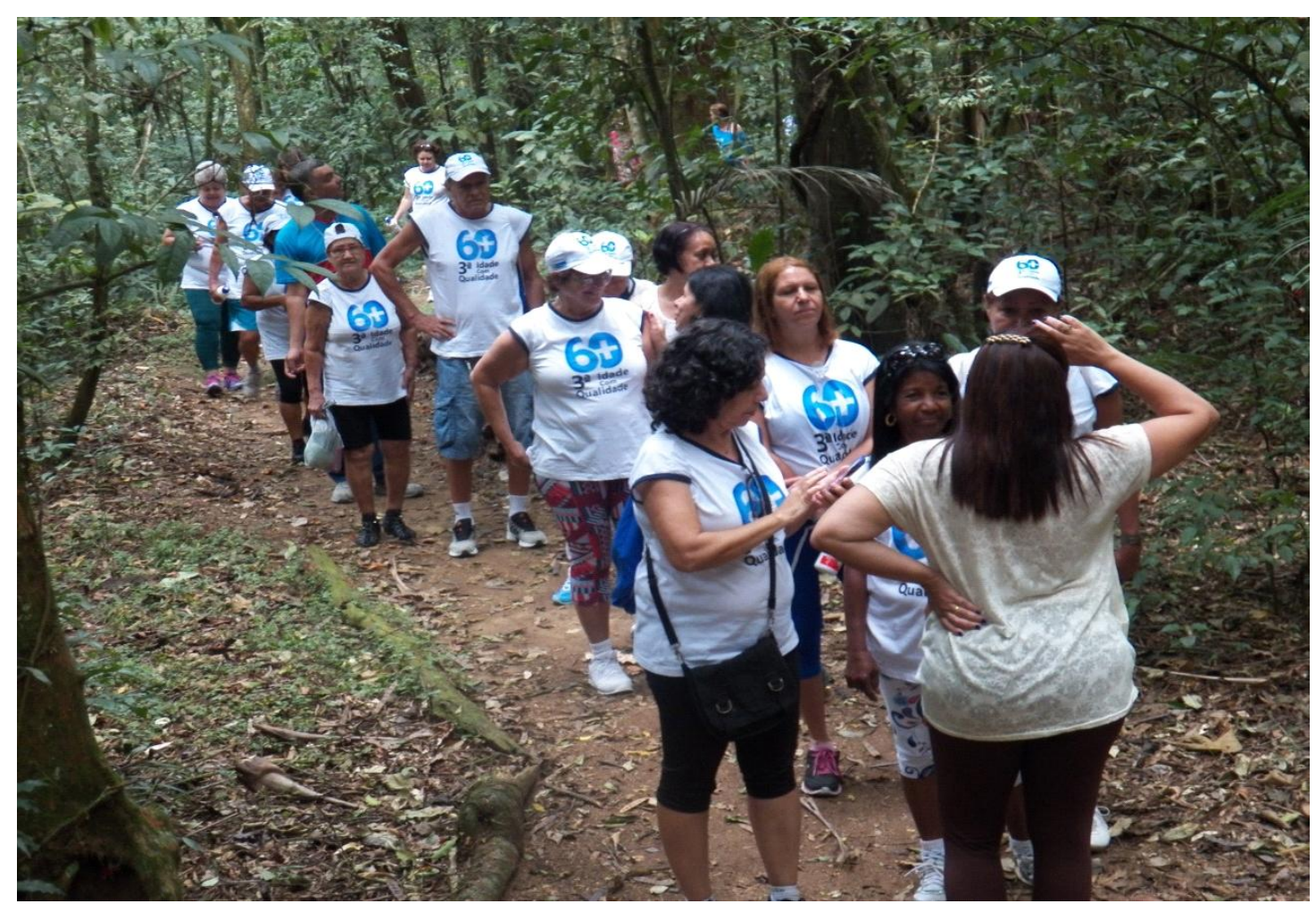

Figura 01. Trilha interpretativa no PARNASO com grupo da $3^{\mathrm{a}}$ idade/Fonte: Arquivo SEMA-Guapimirim

\section{- Soltura de animais silvestres}

As atividades de soltura de animais silvestres foram realizadas na ARIE de Citrolândia. Foi realizada a soltura de 1 jacaré, 1 lagarto e aproximadamente 300 pássaros. Participaram da soltura de animais silvestres, alunos da rede municipal de ensino e pacientes do centro de atendimento psicossocial (CAPS).

Os animais silvestres utilizados na soltura são oriundos do Centro de Triagem de Animais Silvestres (CETAS) em Seropédica, localizado na BR-465, Km-3,5, Floresta Nacional Mário Xavier, Seropédica/RJ.

O CETAS é um empreendimento autorizado pelo IBAMA, conduzido somente por pessoa jurídica, que tem por finalidade receber, identificar, marcar, triar, avaliar, recuperar, reabilitar e destinar animais silvestres provenientes da ação da físcalização, resgate ou entrega voluntária de particulares (MMA, 2015).

Após análise, os animais que apresentam condições de retornar ao ambiente natural, são destinados aos programas de soltura (Figura 2). 


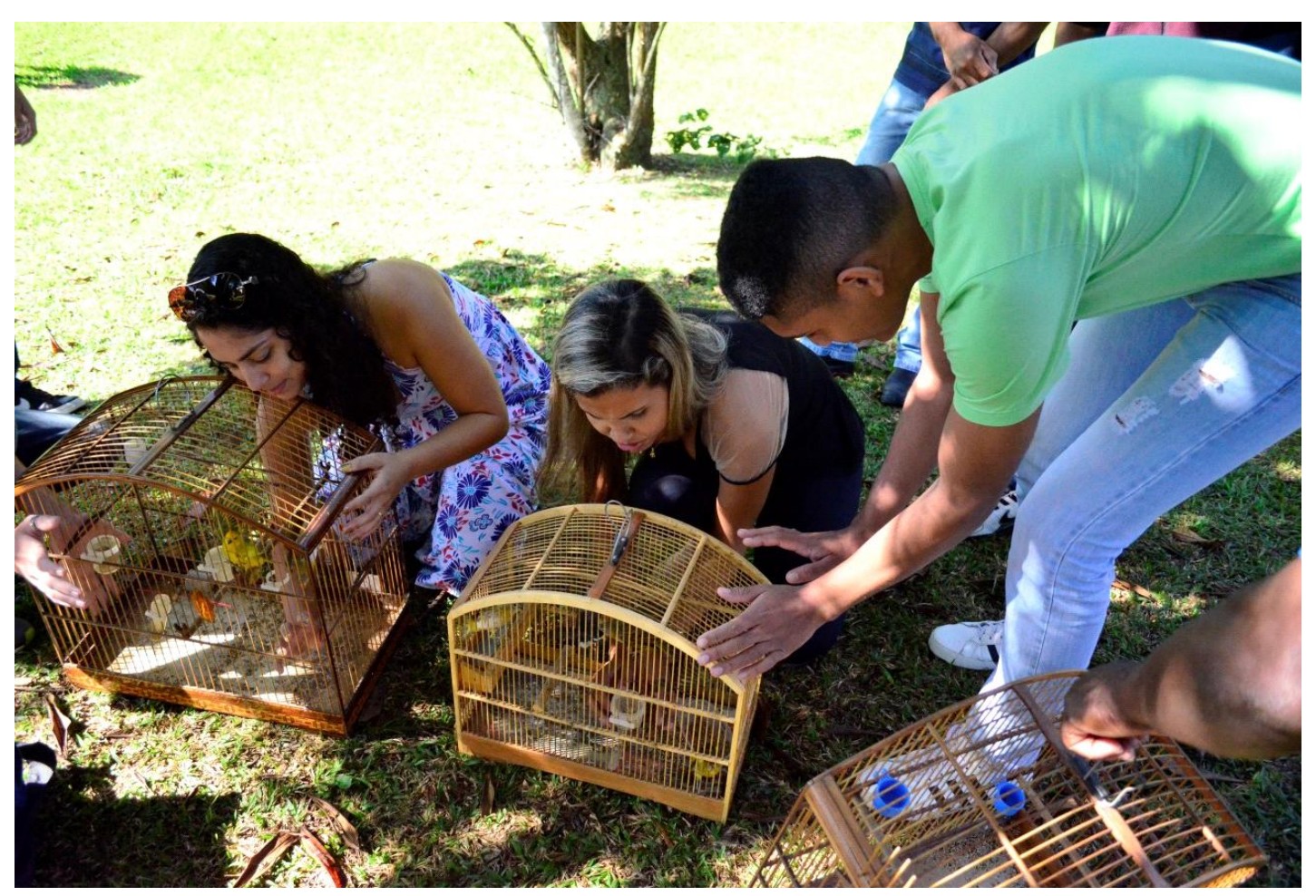

Figura 02. Soltura de pássaros na ARIE de Citrolândia/Fonte: Arquivo SEMA-

Guapimirim

\section{- Plantio de mudas}

Em datas comemorativas, são realizadas palestras destacando a função da vegetação no ambiente e a importância da sua preservação. Culminando com o plantio de mudas na Unidade de Conservação.

\section{- Visitas Técnicas}

Aproveitando o vínculo com as UCs, levamos nossos funcionários para visitas técnicas a estas áreas, com o intuito de que este possa estar familiarizado com a política de uso público destas e, ainda, enfatizar a importância das ações conjuntas no âmbito fiscalizatório, campanhas e treinamento dos novos profissionais da SEMA Guapimirim e de outras secretarias.

\section{- Cursos}

Foi realizado um Curso de Introdução a Fotografia de Natureza, no Parque Nacional da Serra dos Órgãos, sede Guapimirim. Durante o Curso os participantes puderam ter contato com a natureza, conhecer de perto as maravilhas naturais da cidade, proporcionando a apreciação e a valorização do ambiente, além de aprender algumas técnicas de fotografia.

Participaram do Programa Parque Escola, alunos da rede municipal, professores, funcionários da SEMA, pacientes do CAPS, grupos de idosos e demais pessoas tanto da 
comunidade quanto de outros municípios, totalizando aproximadamente 360 pessoas, conforme dados contidos nas Figuras 03 e 04.

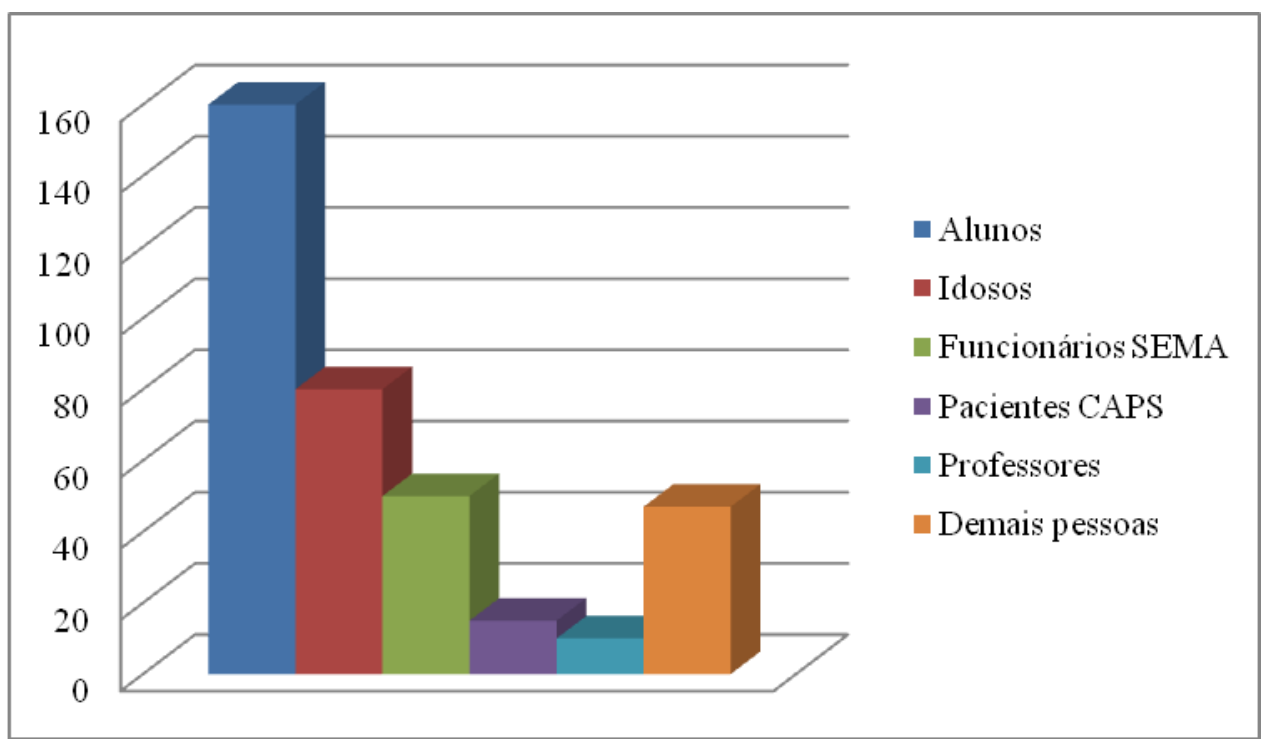

Figura 03. Número de pessoas que participaram do Programa Parque Escola por grupo

(Setembro de 2013 a Maio de 2015)

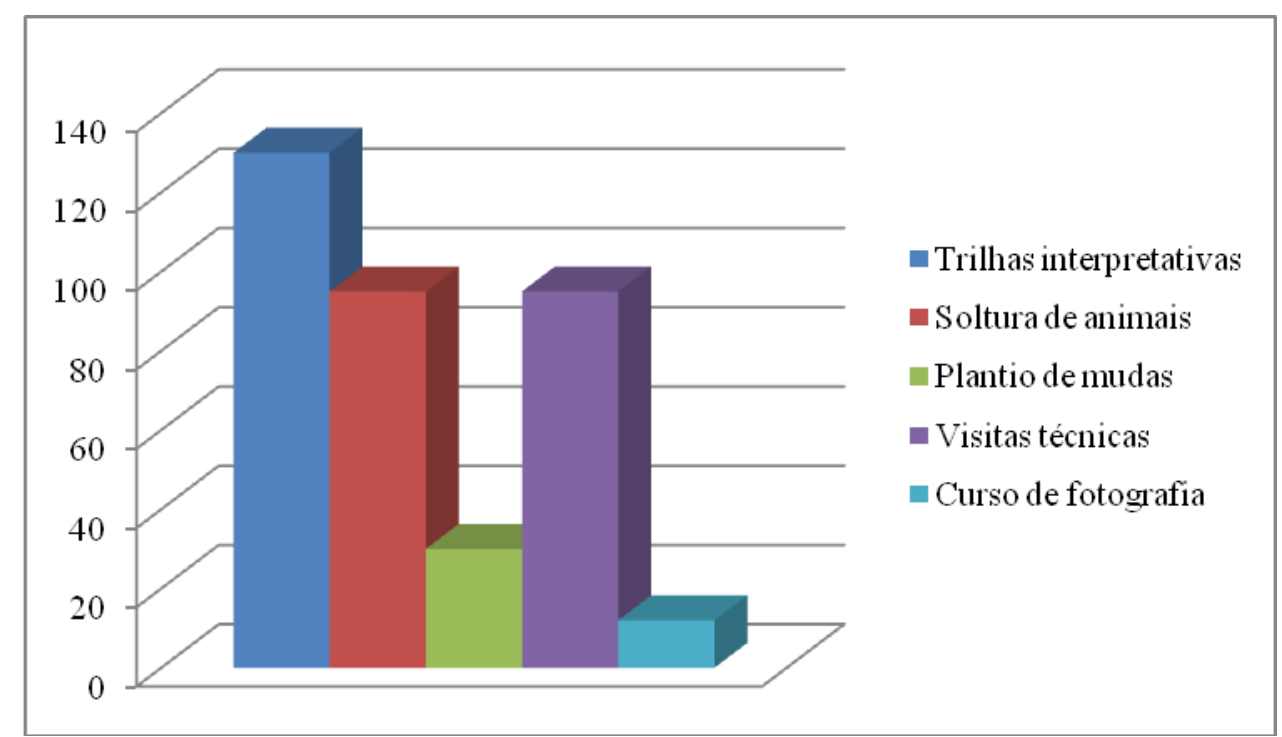

Figura 04. Número de participantes por atividade do Programa Parque Escola (Setembro de 2013 a maio de 2015) 


\section{COMENTÁRIOS SOBRE AS EXPERIÊNCIAS DO PROJETO}

O primeiro contato do grupo com as trilhas mostrou que não conheciam as recomendações básicas para caminhadas e interpretação em trilhas. Isto era evidenciado nas primeiras caminhadas no parque pela desatenção, excesso de conversas paralelas e pelo timbre de voz elevado, fato que seria suficiente para afugentar algumas espécies que poderiam ser identificadas direta ou indiretamente. Inclusive, este comportamento não difere muito de grupos de alunos, professores, técnicos e idosos quando apresentados a uma atividade pedagógica com trilhas.

No entanto, na percepção dos problemas ambientais ao longo das trilhas como os resíduos (lixo) deixados pelos visitantes e a caça ilegal mostrou que os alunos tinham claro, para si, a oportunidade de possibilitar uma reflexão e sensibilização para os agravos ocorridos no ambiente em que estão inseridos. Isto revelou o comprometimento, a ressignificação de valores, a integração e a relação dos seres humanos com a natureza.

Uma outra perspectiva mostra que as trilhas são espaços físicos onde podem haver pontos de parada em determinados trechos relacionadas com o conteúdo do currículo trabalhado em sala de aula, sendo necessário planejar o que os alunos poderão observar durante a caminhada, materiais, recursos, abordagens e atividades a serem utilizadas. Na percepção dos visitantes, em geral, as trilhas são utilizadas para fỉns recreativos, de lazer ou de esporte. No entanto, os grupos guiados por nossa equipe mostram uma maior preocupação em utilizar as trilhas para outros fins, ou seja, como uma ferramenta pedagógica preocupada com a discussão das questões ambientais da região.

Os grupos guiados são confrontados com trilhas situadas em uma área florestal bem preservada, nas quais se percebe no percurso, vegetação original da Mata Atlântica.

O destaque deste trabalho nestes espaços naturais fica por conta da riqueza dos diálogos entre os participantes do grupo, principalmente das crianças menores que se mostram muito à vontade em um ambiente natural, solicitando informações sobre aspectos e detalhes da flora e fauna e da ação humana alterando os ambientes, enfatizando detalhes de uma árvore, as relações ecológicas entre os seres que interagiam com ela, o papel dos decompositores (fungos) na natureza, a necessidade do respeito com as formas de vida do Parque, desde um inseto às aves que ali transitam em busca de alimento e refúgio.

Nossos objetivos propostos para essas atividades, em despertar nos participantes do Programa Parque Escola a reflexão sobre valores ambientais, como o cuidado com as formas de vida e sua sensibilização sobre as áreas naturais, parecem ter sido atingidos.

Numa avaliação das caminhadas desenvolvidas pelo Programa, mostra que a participação dos professores e de alguns pais é muito expressiva e que o diálogo e a 
(Ww.periodicos.uff.br/uso_publico

reflexão-ação sobre o problema estabeleceram um processo de evolução das representações e da percepção ambiental dos mesmos.

\section{CONSIDERAÇÕES FINAIS}

Confirmando alguns aspectos da fundamentação deste trabalho, conclui-se que através da investigação das representações e da percepção da problemática ambiental e das relações dos seres humanos com a natureza, pode-se constatar a viabilidade do desenvolvimento de atividades pedagógicas de sensibilização, sejam elas em espaços naturais ou mesmo em unidades de conservação.

Embora a educação ambiental seja um processo lento, precisamos manter a continuidade das ações, para que se consiga promover transformações na sociedade, pois no futuro, provavelmente poderemos vislumbrar os efeitos do trabalho desenvolvido.

\section{REFERÊNCIAS BIBLIOGRÁFICAS}

BRASIL. Lei $n^{\circ}$ 9.985, de 18 de julho de 2000 e Decreto $n^{0} 4.340$, de 22 de agosto de 2002. Sistema Nacional de Unidades de Conservação da Natureza - SNUC. 2.ed.aum. Brasília: MMA/SBF, 2002.

CAMPANILI, M e SCHAFFER, W.B. (org). Mata Atlântica - Manual de Adequação Ambiental. Ministério do Meio Ambiente, 2010.

CRONEMBERGER, C.; CASTRO, E. B. V. (org). Ciência e conservação na Serra dos Órgãos. Instituto Chico Mendes de Conservação da Biodiversidade. Brasília: Ibama, 2007.

IBAMA (Instituto Brasileiro do Meio Ambiente e dos Recursos Naturais Renováveis). Plano de Manejo da Área de Proteção Ambiental de Guapimirim. IBAMA, 2004.

ICMBio (Instituto Chico Mendes de Conservação da Biodiversidade). Plano de Manejo Estação Ecológica da Guanabara. ICMBio, 2012.

INEA - Instituto Estadual do Ambiente. Parque Estadual dos Três Picos: plano de manejo/resumo executivo. Rio de Janeiro: INEA, 2013.

MMA - Ministério do Meio Ambiente. Centro de Triagem de Animais Silvestres. Disponível em: < http://www.ibama.gov.br/perguntas-frequentes/centro-de-triagem-deanimais-silvestres-cetas > Acesso: 13/04/2015. 